\title{
A Valuable Upgrade to the Portfolio of Cycloaddition Reactions.
}

\author{
John C. Walton ${ }^{*[a]}$
}

Cycloadditions maintain an aura of scientific glamour because of their almost magical organization of multiple components and because of the elegant orbital symmetry rules that underpin them. Cyclotrimerizations are a sub-group in this reaction portfolio, with $[2+2+2]$ cycloadditions being the most familiar. The archetype of this group is the combination of three alkynes to produce benzenes [Scheme 1, equ. (a)]. Many related versions are known including those with other unsaturated moieties, those in which two of the unsaturated units are tethered together, thus lowering the entropy barrier [Scheme 1, equ. (b)] and preparative versions permitting control of regio-, chemo- and stereo-selectivity. ${ }^{[1]}$
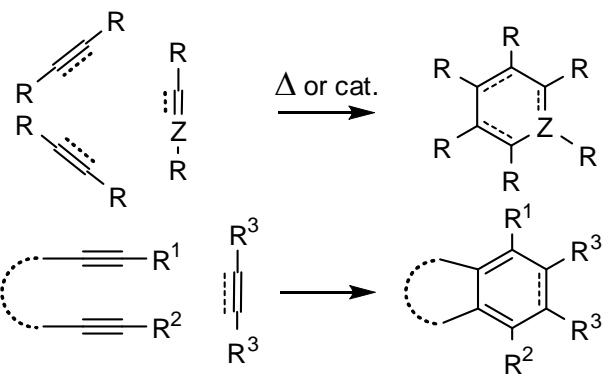<smiles></smiles><smiles>[R]C1([R7])C([R7])([R7])C1([R7])[R7]</smiles>

wide variety of precursors including carbenes, carbenoids, diazocompounds and ylides participate in $[2+1]$ cycloadditions to alkenes producing cyclopropanes. Furthermore, enantioselective versions, often making use of metal catalysts with chiral ligands, are available. ${ }^{[3]}$
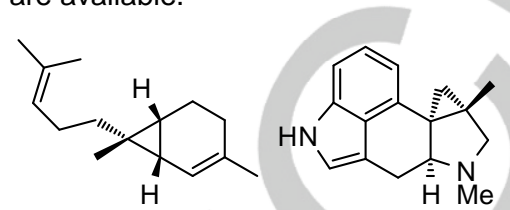

$( \pm)$-sesquicarene (士 )-5-epi-cycloclavine<smiles>NC1(C(=O)O)CC1</smiles>

phytohormone precursor

Scheme 2. Selected natural products and bioactive molecules containing cyclopropane rings

Aryl methyl ketones $\mathbf{1}$ are stable and non-toxic and so are much more attractive reagents than the haloforms, diazocompounds, ylides etc. required in conventional cyclopropane syntheses. For that reason, the discovery in 2014 by Nacci, Monopoli and co-workers of means to deploy them as the 1-Catom sources in $[2+1]$ cycloadditions represented a noteworthy breakthrough. ${ }^{[4]}$ They showed that $\mathrm{Pd}(\mathrm{OAc})_{2}$ and $\mathrm{Cu}(\mathrm{OAc})_{2}$ in aerated tetrabutylammonium acetate at $100^{\circ} \mathrm{C}$ catalyzed the formation of cyclopropanes from aryl methyl ketones and styrenes. The aryl (or heteroaryl) rings were shown to be essential structural features because aliphatic and other ketone types were unreactive or yielded alternative products. These authors proposed that the ketones formed oxa- $\pi$-allylpalladium complexes that coupled with styrene to provide 6-member ring oxa- $\pi$-allylpalladium complexes (analogous to 9 in Scheme 3 ). Reductive elimination of $\mathrm{Pd}^{0}$ then generated the 3-member rings.

Stimulated by this, Antonchick and Manna discovered a simpler system comprising Cul, bipy and di-tert-butylperoxide (DTBP) in chlorobenzene that catalyzed cyclopropanations of maleimides by the same aryl methyl ketones. ${ }^{[5]}$ They then conceived the insightful idea that if an alkene component could be generated in situ, and from the same ketone then, with an appropriate experimental protocol, a unique one pot $[1+1+1]$ cyclotrimerization might be realizable. ${ }^{[6]}$ Remarkably they achieved this unique cascade in practice when acetophenones 1 were treated with Cul, employing 4,4'-di-tert-butyl-2,2'-bipyridine ligands, with DTBP as oxidant in chlorobenzene solvent. The copper catalyst transformed each of 20 ketones, irrespective of either electron-releasing or electron-withdrawing substituents in their aryl rings, into triaroyl-cyclopropanes $\mathbf{1 0}$ in yields of $35-88 \%$. Furthermore, these extraordinary $[1+1+1]$ cyclotrimerizations took place stereoselectively (Scheme 3 ).

Evidence of a radical mechanism was provided, with 1,4diketones (shown as enol tautomers 3 in Scheme 3) being obtained from dimerization of aroylmethyl radicals 2 . Oxidation and $\beta$-hydride elimination as shown delivered the trans unsaturated 1,4-diketones 6 needed for [2+1] cycloaddition steps. 
Capture of more radical 2 by acceptors 6 generated tri-aroyl-alkyl radicals 7 . It was proposed that 7 coupled with $\mathrm{Cu}$ (II) to give organocuprates $\mathbf{8}$ and hence to metallocycles $\mathbf{9}$ that reductively eliminated $\mathrm{Cu}(\mathrm{I})$ with ring closure to stereospecifically afford the cyclopropanes 10.

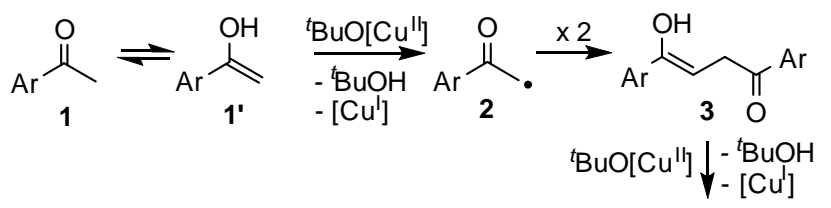

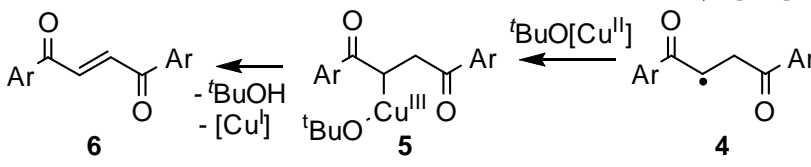

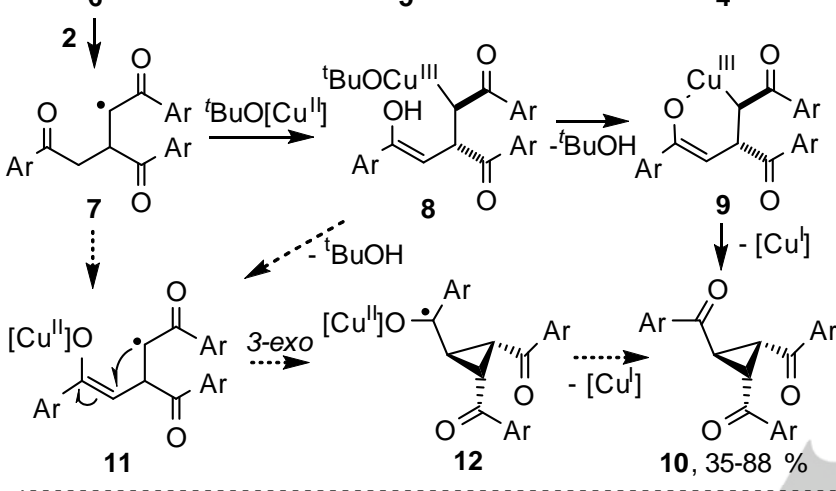

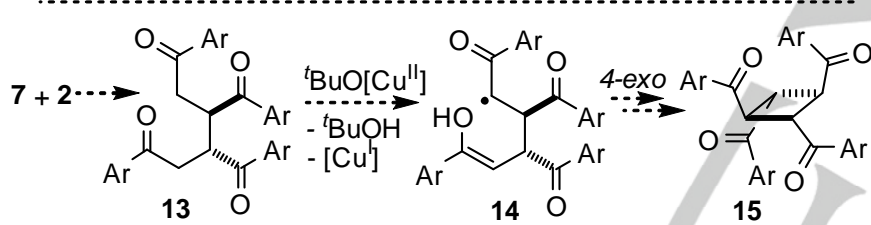

Scheme 3. $[1+1+1]$ Cyclotrimerization of aryl methyl ketones with a tentative mechanism.

This plausible sequence accounts for most features of the process. It seems to imply, however, that aliphatic ketones could also take part in such cycloadditions, whereas no examples were reported. As a possible alternative, $\mathrm{Cu}$ (II)-enolate radicals $\mathbf{1 1}$ might form from $\mathbf{7}$ or $\mathbf{8}$. 3-Exo ring closures of $\mathbf{1 1}$ would be very favourable because of the large benzylic type stabilization in the ring-closed radicals $12 .^{[2 a, 7]}$ Elimination of $\mathrm{Cu}(\mathrm{I})$ would then complete the cyclotrimerization. The intermediacy of $\mathbf{1 2}$ would suitably explain the exclusivity for aryl ketone precursors.

Could the cascade succeed with other ketone types? The $\mathrm{C}(=\mathrm{O}) \mathrm{CH}_{3}$ unit is probably essential because enolization ability is needed and because of steric constraints on coupling and addition steps. The driving force for formation of the strained 3member rings is the large benzylic resonance stabilization of the ring-closed species 12 . If closure actually occurs on reductive elimination from metallocycle 9 it is probable that the transition state develops stabilization akin to that shown in $\mathbf{1 2}$. Cyclotrimerizations of ketones $\mathrm{Z}-\mathrm{C}(=\mathrm{O}) \mathrm{CH}_{3}$, where $\mathrm{Z}$ strongly stabilizes an adjacent radical, might therefore succeed and $Z=$ heteroarene, $\mathrm{RCH}=\mathrm{CH}-, \mathrm{RC} \equiv \mathrm{C}$ - are possible candidates.

Numerous preparative sequences based around the cyclotrimerization products can be expected. Cyclopropanes 10 contain three electron-withdrawing $\mathrm{Bz}$ substituents so ring cleavage by nucleophiles should be facile. ${ }^{[8]}$ The resulting enolates, $\mathrm{BzCH}(\mathrm{Nu}) \mathrm{CH}(\mathrm{Bz}) \mathrm{CH}=\mathrm{C}(\mathrm{Ar}) \mathrm{O}^{-}$, are promising for alkylations of many electron deficient substrates. A large variety of other reagent types are expected to afford ring-opened propene, halo-propane and other derivatives.

The system involves multiple intermediates and so other protocols might direct it down alternative pathways. For example, cross-coupling of radicals $\mathbf{7}$ and $\mathbf{2}$ would produce tetrabenzoylbutane 13. The Cu reagent could generate radical $\mathbf{1 4}$ from an enol of this and then a $[1+1+1+1]$ cyclotetramerization yielding cyclobutane 15 might take place either via a metallocycle or via a copper enolate analogous to $\mathbf{1 1}$ (homo-dimerization of radicals 4 could provide an alternative entry to cyclotetamerizations). Note however that formation of tertiary radicals from 13 might compete and that appropriate control of the concentrations of radicals $\mathbf{7}$ and $\mathbf{2}$ would be difficult to arrange.

Antonchick and Manna's intriguing discovery extends the portfolio of cycloaddition processes in a mechanistically fascinating and totally unexpected direction. It marshals three simple components and assembles them efficiently into energyrich structures ready for exploitation in a multitude of different ways. It is sure to stimulate the discovery of new variants and varieties as well as useful applications.

\section{Acknowledgement}

The author thanks EaStCHEM for financial support.

Keywords: carbocycles $\bullet$ copper $\bullet$ cyclotrimerization $\bullet$ radicals $\bullet$ synthetic methods.

[1] For reviews see: (a) S. Kotha, E. Brachmachary, K. Lahiri, Eur. J. Org. Chem. 2005, 4741-4767; (b) G. Dominguez, J. Perez-Castells, Chem. Soc. Rev. 2011, 40, 3430-3444; (c) M. Amatore, C. Aubert, Eur. J. Org. Chem. 2015, 265-286.

[2] See for example: (a) A. de Meijere, ed. Carbocyclic three- and fourmembered ring compounds, Volume E17c, Cyclopropanes, Thieme, Stuttgart, 1997, pp. 1949-2694; (b) C. A. Carson, M. A. Kerr Chem. Soc. Rev. 2009, 38, 3051-3060; (c) D. Y. K. Chen, R. H. Pouwer, J. A. Richard, Chem. Soc. Rev. 2012, 41, 4631-4642; (d) P. Tang, Y. Qin, Synthesis 2012, 44, 2969-2984; (e) T. F. Schneider, J. Kaschel, D. B. Werz, Angew. Chem. Int. Ed. 2014, 53, 5504-5523; Angew. Chem. 2014, 126, 56085628.

[3] (a) H. Pellissier, Tetrahedron 2008, 64, 7041-7095; (b) M.-N. Roy, V. N. G. Lindsay, A. B. Charette, in Science of Synthesis, Stereoselective Synthesis (Eds.: J. G. De Vries, G. A. Molander, P. A. Evans), Georg Thieme, Stuttgart, 2011, 1, 731-817; (c) G. Bartoli, G. Bencivenni, R. Dalpozzo, Synthesis 2014, 46, 979-1029; (d) A. Ford, H. Miel, A. Ring, C. N. Slattery, A. R. Maguire, M. A. McKervey, Chem. Rev. 2015, 115, 9981-10080.

[4] P. Cotugno, A. Monopoli, F. Ciminale, A. Milella, A. Nacci, Angew. Chem. Int. Ed. 2014, 53, 13563-13567; Angew. Chem. 2014, 126, 1378113785.

[5] S. Manna, A. P. Antonchick, Angew. Chem. Int. Ed. 2015, 54, 1484514848; Angew. Chem. 2015, 127, 15058-15061.

[6] S. Manna, A. P. Antonchick, Angew. Chem. Int. Ed. DOI: 10.1002/anie.201600807; Angew. Chem.DOI: 10.1002/ange.201600807.

[7] J. Friedrich, M. Dolg, A. Gansaeuer, D. Geich-Gimbel, T. Lauterbach, J. Am. Chem. Soc. 2005, 127, 7071-7077.

[8] See for example: (a) S. Danishefsky, Acc. Chem. Res. 1979, 12, 66-72; (b) H.-U. Reissig, R. Zimmer, Chem. Rev. 2003, 103, 1151-1196; (c) O. Lifchits, A. B. Charette, Org. Lett. 2008, 10, 2809-2812. 


\section{Entry for the Table of Contents}

Layout 1:

\section{HIGHLIGHT}

Recently Antonchick and Manna described a unique annulation that knits together three acetophenones to construct cyclopropanes. The cascade is mediated by organocopper and free radical species and amounts to the first known [1+1+1] cyclotrimerization. It works well for ketones having electron-deficient or electron-rich substituents in their aryl rings.

\section{J. C. Walton*}

Page No. - Page No.

A Valuable Upgrade to the Portfolio of Cycloaddition Reactions

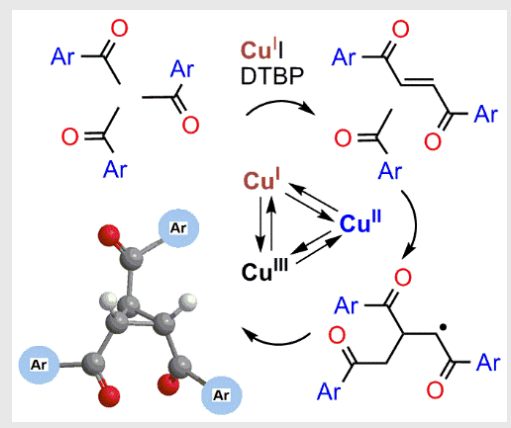

